\title{
Stability constants of cerium(IV) complexes with 8-hydroxyquinoline and 8-hydroxy-7-iodoquinoline- 5-sulfonic acid
}

\begin{abstract}
Thermodynamic stability of cerium(IV) complexes formed in the initial stage of oxidation of 8-hydroxyquinoline and 8-hydroxy-7-iodoquinoline-5-sulfonic acid by cerium(IV) sulfate were studied spectrophotometrically and $\mathrm{pH}$-potentiometrically with the aid of differential kinetic methods at an ionic strength $I=2 \mathrm{~mol} / \mathrm{L}$ within the $\mathrm{pH}$ range of $0.5-2.5$ in a sulfuric acid medium and at temperatures of 275.15-289.15 K. Composition of these complexes, the form of organic ligand existence therein, and their stability constants were determined.
\end{abstract}

Keywords: 8-hydroxyquinoline, 8-hydroxy-7-iodoquinoline-5-sulfonic acid, cerium, coordination compounds, stability constants
Volume 7 Issue 5 - 2018

\author{
Olga OVoskresenskaya,' Nina A Skorik ${ }^{2}$ \\ 'Laboratory of Information Technologies, Joint Institute for \\ Nuclear Research, Russia \\ ${ }^{2}$ Department of Inorganic Chemistry, Tomsk State University, \\ Russia
}

Correspondence: Olga Voskresenskaya, Laboratory of Information Technologies, Joint Institute for Nuclear Research, 6 Joliot Curie, I41980 Dubna Moscow Region, Russia,Tel +7916 373 8347, Email voskr@jinr.ru

Received: August 06, 2018 | Published: September 04, 2018

\section{Introduction}

8-hydroxyquinoline, its derivatives and metal-ion complexes exhibit multifunctional properties, including antioxidant, antineurodegenerative, anticancer, anti-inflammatory and antidiabetic activities. The interest in 8-hydroxyquinolines and their metal complexes has grown in the last two decades exponentially as they are privileged structures for the design of new drug candidates that exert a host of biological effects on various targets. ${ }^{1,2}$

The derivatives of 8-hydroxyquinoline and their compounds with rare earth elements (REE) are widely used in analytical chemistry. The luminescent properties of REE complexes with 8-hydroxyquinoline and its derivatives are employed in luminescent analysis, technologies for creating materials with photo- and electroluminescent properties for optoelectronics, photonics, chemo- and biosensorics. ${ }^{3,4}$ 8-hydroxyquinoline is used in the extraction and spectrophotometric determination of cerium(IV), and cerium(IV) is employed in the oxydimetric determination of 8 -hydroxyquinoline. ${ }^{5}$

However, there are no data on the thermodynamic stability of cerium(IV) complexes with 8-hydroxyquinoline (HOxiN) and 8-hydroxy-7-iodoquinoline-5-sulfonic acid $\left(\mathrm{H}_{2} \mathrm{Fer}\right)$ in the literature. In this paper, the kinetic analogues of the thermodynamic methods for investigating the formation of variable-valence metal complexes are applied to the study of the stability of cerium(IV) complexes ${ }^{6,7}$ formed in the $\mathrm{Ce}^{4+}-\mathrm{SO}_{4}^{2-}-\mathrm{R}$ systems with $\mathrm{R}=\mathrm{HOxiN}$ and $\mathrm{H}_{2}$ Fer,<smiles>Oc1cccc2cccnc12</smiles>

HOxN<smiles>O=S(=O)(O)c1cc(I)c(O)c2ncccc12</smiles>

$\mathrm{H}_{2} \mathrm{Fer}$

\section{Materials and procedure}

\section{Reagents}

8-hydroxyquinoline $\left(\mathrm{C}_{9} \mathrm{H}_{7} \mathrm{ON}\right)$ and 8-hydroxy-7-iodoquinoline5 -sulfonic acid $\left(\mathrm{C}_{9} \mathrm{H}_{6} \mathrm{O}_{4} \mathrm{NIS}\right)$ of the analytically pure grade and cerium(IV) sulfate tetrahydrate $\mathrm{Ce}\left(\mathrm{SO}_{4}\right)_{2} \cdot 4 \mathrm{H}_{2} \mathrm{O}$ of analytical reagent grade were used as starting materials. In all solutions, an ionic strength of $I=2 \mathrm{~mol} / \mathrm{L} \quad\left\{c_{\mathrm{SO}_{4}}=0.67 \mathrm{~mol} / L\right\}$ was generated with analytical reagent grade ammonium sulfate. The initial solutions were prepared from precisely weighed portions. The content of cerium(IV) in a freshly prepared solution of cerium(IV) sulfate was determined by back titration with Mohr's salt in the presence of ferroin ${ }^{5}$ before and after an experiment.

\section{Instrumantal analysis}

The optical density was recorded in time using a SPECORD UV VIS recording spectrophotometer equipped with a temperaturecontrolled cell holder for rectangular quartz cells with an optical path length $l=1 \mathrm{~cm}$ and a KF-5 photoelectric colorimeter with a MEA4 recording device and a temperature controlled case for standard cells with $l(10.00 \pm 0.01) \times 10^{-1} \mathrm{~cm}$. The $\mathrm{pH}$ value was measured in the reaction mixture, after the recording of the optical density $(\tau \approx 1 \mathrm{~min}$ and also $\tau \approx 10 \mathrm{~min}$ ), and in the cerium(IV) solutions with a DATA METER precision $\mathrm{pH}$ meter. In the measurements, the concentration scale was used. The glass electrode was calibrated against $\mathrm{HCl}$ solutions of know concentration at $I=2$, since the $\mathrm{pHs}$ measured did not exceed 3.0-3.5. Buffer solutions were used for the initial correction of the $\mathrm{pH}$-meter scale. The instant at which the mixing vessel whereto the starting components were placed was turned upside down, was taken as the time of reaction onset, $\tau=0$. Kinetic measurements were carried out at $515 \mathrm{~nm}$, where the greatest increase in the differences $\Delta D^{0}=D^{0}-D_{\mathrm{M}}$ and $\Delta \dot{D}^{0}=\dot{D}^{0}-\dot{D}_{\mathrm{M}}$ were observed with increasing $\mathrm{pH}$ ( $D^{0}$ is the initial value of the optical density of the reaction mixture at the initial time $\tau=0$ found by linear extrapolation of the kinetic curves in the coordinates $\log D-\tau$, where their linearity took place; $D_{\mathrm{M}}$ the optical density of the metal ion 
solution, $\dot{D}_{\mathrm{M}} \approx 0$ is the rate of its change; and $-\dot{D}^{0} \equiv \partial D / \partial \hat{\mathrm{o}}$, $\mathrm{s}^{-1}$, is the initial rate of the redox decomposition of the complexes). The initial equilibrium concentration of the cerium(IV) complexes were determined at the instant of time $\tau=0$ according to formula $c_{1}^{-0}=-\left(\dot{D}^{0}-\dot{D}_{M}\right) /\left(\dot{D}_{\infty}^{0}-\dot{D}_{M}\right) c_{M}\left(c_{M} \leq c_{L}\right)$, where $c_{M}$ and $c_{L}$ are the concentrations of test solutions of cerium (IV) and ligands (HOxiN and $\mathrm{H}_{2}$ Fer). Here and below, the line above the symbol stands for the value determined by kinetic means. The maximum value $-D_{\infty}^{0}, s^{-1}$, of the rate $-D^{0}, s^{-1}$, were found by means of the $-D^{0}-p H$ method. ${ }^{6,7}$ The initial rate of the redox decomposition of the complexes was estimated graphically on a semi-log grid using the slope ratio of line $-\dot{D}^{0}=\left(D^{0}-D^{i}\right) /\left(\tau^{0}-\tau^{i}\right)=$ const (Figure 1) and calculated by the linear least squares method.

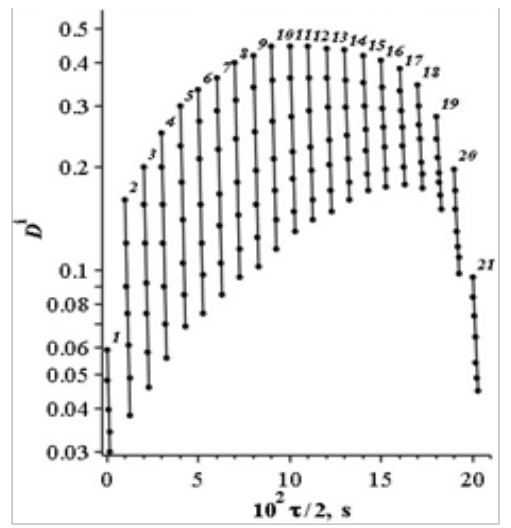

Figure I Pseudo first-order rate curves $D^{i}-\tau^{i}\left(\tau^{i+1}-\tau^{i}=5 c, i=1, \ldots, 5-7\right)$ for the $\mathrm{Ce}^{4+}-\mathrm{SO}_{4}^{2-}-\mathrm{H}_{2}$ Fer system $\left(c_{M+L}=9.53 \times 10^{-4} \mathrm{~mol} / \mathrm{L}\right.$, I= 2 , $T=289.15 \mathrm{~K}, \lambda_{\text {ef }}=515 \mathrm{~nm}$.

\section{Results and discussion}

\section{Composition of complexes}

The metal: Ligand molar ratio in the complex formed at the time of mixing the solutions was established by the isomolar series method $\Delta D^{0}-N_{L}\left(N_{L}\right.$ is the mole fraction of the ligand), adapted to the study of variable-valence metal complexes, and a kinetic analog of this method $(\log D)_{\tau}^{\prime}-N_{L}$, where $(\log D)_{\tau}^{\prime} \equiv \partial \log D / \partial \hat{o}^{6}{ }^{6}$ Figure 2 shows that in the systems $\log \bar{\beta}_{1}$ complexes characterized by a metal:ligand ratio of $1: 1(\mathrm{~mol} / \mathrm{mol})$ are formed at the initial time. The obtained data agree with the data of kinetic studies, ${ }^{8}$ which indirectly indicate the formation of $1: 1(\mathrm{~mol} / \mathrm{mol})$ intermediate complexes in the course of oxidation of 8-hydroxyquinoline and 8-hydroxy-7iodoquinoline-5-sulfonic acid by cerium(IV) in perchlorate medium.i

\section{Ligand speciation}

The form in which organic ligands were present in the complex was determined by analyzing the property- $\mathrm{pH}$ diagrams (Figure 3) by the $\dot{D}^{0}-p H$ method. ${ }^{6}$ The predominant form of cerium(IV) against the sulfate background at $\mathrm{pH}$ studied is the monohydroxo form $\mathrm{CeOH}^{3+} \cdot{ }^{7}$ The number of protons $z$ displaced from the cationic form $\mathrm{HR}^{+}=\mathrm{H}_{2} \mathrm{OxN}^{+}$of the molecule $\mathrm{R}=$ HOxiN and the zwitterionic molecule $\mathrm{H}_{2}$ Fer by the cerium(IV) ion when equilibria

$$
\begin{gathered}
\mathrm{CeOH}^{3+}+\mathrm{H}_{2} \mathrm{OxN}^{+} \stackrel{{ }_{K}}{\leftrightarrow}\left[\mathrm{CeOHH}_{2-\mathrm{z}} \mathrm{R}^{\mathrm{z}-1}\right]^{3-\mathrm{z}+1}+\mathrm{zH}^{+} \\
\mathrm{CeOH}^{3+}+\mathrm{H}_{2} \mathrm{Fer} \stackrel{\leftrightarrow}{\leftrightarrow}\left[\mathrm{CeOHH}_{2-\mathrm{z}} \mathrm{Fer}^{-\mathrm{z}}\right]^{3-\mathrm{z}}+z \mathrm{H}^{+} \\
\bar{K}_{1}=\bar{\beta}_{1}^{e f}\left[\mathrm{H}^{+}\right]^{\bar{z}}
\end{gathered}
$$

were established was estimated graphically as the slope of the dependence of $\mathrm{CeOH}^{3+}$ on $\mathrm{pH}$,

$$
\log \bar{\beta}_{\mathrm{n}}^{\text {ef }}=\log \overline{\mathrm{K}}_{\mathrm{n}}+\bar{z} \mathrm{pH}
$$

as a result of comparison of two $\dot{D}^{0}-p H$ data series.

Effective (depending on the $\mathrm{pH}$ value) stability constants $\bar{\beta}_{\mathrm{n}}^{\text {ef }}$ were calculated using the equation

$$
\bar{\beta}_{1}^{\text {ef }}=\frac{\bar{c}_{1}^{0}}{\left(c_{\mathrm{M}}-\bar{c}_{1}^{0}\right)\left(c_{\mathrm{L}}-\bar{c}_{1}^{0}\right)}
$$

Figure 3 demonstrate that in the course of complexation a $\mathrm{CeOH}^{3+}$ ion displaces two protons $(z=2)$ from $\mathrm{H}_{2} \mathrm{OxN}^{+}$and $\mathrm{H}_{2} \mathrm{Fer}$. The latter can be accompanied by the formation of chelate complexes and the closure of the 5-membered cycles.

\section{Stability constants}

For the complexation equilibrium with anionic species $R^{m-}=\mathrm{OxiN}^{-}, \operatorname{Fer}^{2-}(m=1,2)$,

$$
\begin{gathered}
\mathrm{CeOH}^{3+}+\mathrm{R}^{\mathrm{m}-} \stackrel{\bar{\beta}_{1}}{\leftrightarrow}[\mathrm{CeOHR}]^{(3-\mathrm{m})+} \\
\bar{\beta}_{1}=\bar{\beta}_{1}^{\text {ef }} f_{2}, f_{2}=1+\sum_{i=1}^{2} B_{\mathrm{i}}[H]^{\mathrm{i}}
\end{gathered}
$$

the concentration stability ${ }^{i=1}$ constants $\bar{\beta}_{1}$ were calculated for each point of function $\log \bar{\beta}_{1}=\log \bar{\beta}_{1}^{\text {ef }}+\log f_{2}$ and by averaging the values obtained according to series $\dot{D}^{0}-p H$. Calculations were performed using the following logarithms of the cumulative protonation constants of the anionic species $R^{m-}: \log B_{1}=p K_{2}=9,56, \log B_{2}=\lg B_{1}+p K_{1}=14,76, p K_{1}=5,20\left(\mathrm{OxiN}^{-}\right){ }^{9}$ $\log B_{1}=6,87, \log B_{2}=9,57, p K_{1}=2,70\left(\mathrm{Fer}^{2-}\right) .{ }^{10} \quad$ Note that according to, ${ }^{10,11}$ the values of the dissociation constants $K_{1}, K_{2}$ obtained in ${ }^{10}$ for 7-iodo-8-hydroxyquinoline-5-sulfonic acid characterize the equilibria

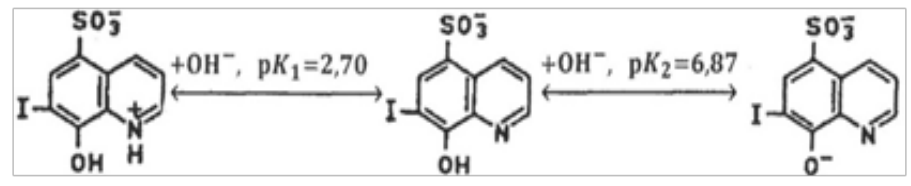

The confidence interval for average values of these thermodynamic characteristics, along with the optical parameters of the complexes, was calculated at a sample size of $N=14-16$ with a confidence level of 0.95 using the STATOBRABOTKA statistical processing program. ${ }^{12}$ The averaged values of $\log \bar{\beta}_{1}$ determined using the method $\dot{D}^{0}-p H$ were $15.54 \pm 0.13$ for the $[\mathrm{CeOHOxiN}]^{2+}$ complex (Table 1) and $12.38 \pm 0.11$ for the complex $[\mathrm{CeOHFer}]^{+}$(Table 2). 
The constancy of the calculated $\log \bar{\beta}_{1}$ value within the series $\dot{D}^{0}-p H$ indicates that the basic equilibria in solution are taken into account correctly. Lower stability of the complex [CeOHFer] $]^{+}$ compared to $[\mathrm{CeOHOxiN}]^{2+}$ is due to the presence of the electron withdrawing groups (sulfonic acid group and iodine atom) in the molecule $\mathrm{H}_{2}$ Fer

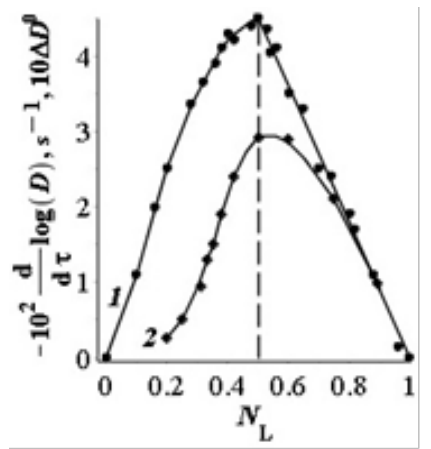

Figure 2 Diagrams: (I)

$\Delta D^{0}-N_{L}\left(c_{M+L}=9.53 \times 10^{-4} \mathrm{~mol} / L, I=2, T=289.15 \mathrm{~K}, \lambda_{\text {ef }}=515 \mathrm{~nm}\right)$ for the system $\mathrm{Ce}^{4+}-\mathrm{SO}_{4}^{2-}-\mathrm{H}_{2} \mathrm{Fer},(2)$

$\mathrm{Ce}^{4+}-\mathrm{SO}_{4}^{2-}-\mathrm{H}_{2} \operatorname{Fer}\left(c_{M}=c_{L}=4.77 \times 10^{-4} \mathrm{~mol} / \mathrm{L}, \mathrm{I}=2, \mathrm{~T}=289.15 \mathrm{~K}, \lambda_{\text {ef }}=515 \mathrm{~nm}\right)$ for the system $\mathrm{Ce}^{4+}-\mathrm{SO}_{4}^{2-}-\mathrm{HOxiN}$.

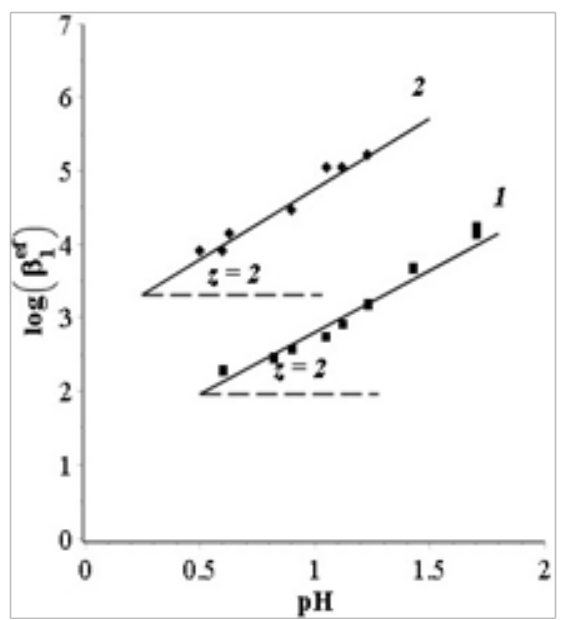

Figure 3 Diagrams of the dependence of the logarithm of the effective stability constant of complexes on the $\mathrm{pH}$. System: (I)

$\mathrm{Ce}^{4+}-\mathrm{SO}_{4}^{2-}-\mathrm{HOxiN}\left(c_{M}=1.56 \times 10^{-4}, c_{L}=4.69 \times 10^{-4} \mathrm{~mol} / \mathrm{L}, I=2, \mathrm{~T}=289.15 \mathrm{~K}, \lambda_{e f}=515 \mathrm{~nm}\right)$ (2)

$\mathrm{Ce}^{4+}-\mathrm{SO}_{4}^{2-}-\mathrm{H}_{2} \operatorname{Fer}\left(c_{M}=c_{L}=4.77 \times 10^{-4} \mathrm{~mol} / \mathrm{L}, I=2, T=289.15 \mathrm{~K}, \lambda_{e f}=515 \mathrm{~nm}\right)$

Table I Stability constants of the complex $[\mathrm{CeOHOxiN}]^{2+}$ determined by the $\dot{D}^{0}-p H$ method $\dot{D}_{\infty}^{0}=2.03 \times 10^{-2} \mathrm{~s}^{-1}, c_{\mathrm{L}}=4.69 \times 10^{-4}$ $\left.\mathrm{mol} / \mathrm{L}, \dot{D}_{\infty}^{0}=2.03 \times 10^{-2} \mathrm{~s}^{-1}, D_{\infty}^{0}=0.162, I=2, T=289.15 \mathrm{~K}, \lambda_{\text {ef }}=515 \mathrm{~nm}, I=\mathrm{Icm}\right)^{*}$

\begin{tabular}{llllll}
\hline $10 \dot{D}^{0}, \mathrm{~s}^{-1}$ & $10 \Delta D^{0}$ & $\mathrm{pH}$ & $10^{4} \bar{c}_{1}^{0}, \mathrm{~mol} / L$ & $\log \bar{\beta}_{1}^{\mathrm{ef}}$ & $\log \bar{\beta}_{1}$ \\
\hline-0.16 & 0.13 & 0.6 & 0.12 & 2.27 & 15.83 \\
-0.23 & 0.19 & 0.82 & 0.18 & 2.46 & 15.58 \\
-0.28 & 0.23 & 0.9 & 0.22 & 2.57 & 15.53 \\
-0.39 & 0.31 & 1.05 & 0.31 & 2.75 & 15.41 \\
-0.51 & 0.42 & 1.12 & 0.4 & 2.91 & 15.43 \\
-0.77 & 0.6 & 1.23 & 0.6 & 3.19 & 15.49 \\
-1.28 & 1.03 & 1.43 & 1 & 3.68 & 15.58 \\
-1.64 & 1.38 & 1.7 & 1.28 & 4.13 & 15.49 \\
\hline
\end{tabular}

${ }^{*} \log \bar{\beta}_{1}=15.54 \pm 0.13$.

Table 2 Stability constants of the complex $[\mathrm{CeOHFer}]^{+}$determined by the $\dot{D}^{0}-p H$ method $\left(c_{M}=c_{L}=4.77 \times 10^{-4} \mathrm{~mol} / \mathrm{L}, \dot{D}_{\infty}^{0}=6.30 \times 10^{-2} \mathrm{~s}^{-1}\right.$, $\left.D_{\infty}^{0}=0.745, I=2, T=289.15 \mathrm{~K}, \lambda_{\text {ef }}=515 \mathrm{~nm}, I=\mathrm{Icm}\right)^{*}$

\begin{tabular}{llllll}
\hline $10 \dot{D}^{0}, \mathrm{~s}^{-1}$ & $10 \Delta D^{0}$ & $\mathrm{pH}$ & $10^{4} \bar{c}_{1}^{0}, \mathrm{~mol} / L$ & $\log \bar{\beta}_{1}^{\text {ef }}$ & $\log \bar{\beta}_{1}$ \\
\hline-0.38 & 3.46 & 0.5 & 2.86 & 3.9 & 12.47 \\
-0.38 & 4.73 & 0.6 & 2.88 & 3.91 & 12.28 \\
-0.34 & 4.07 & 0.63 & 2.59 & 4.15 & 12.46 \\
-0.5 & 6.2 & 0.9 & 3.79 & 4.46 & 12.23 \\
-0.55 & 6.48 & 1.05 & 4.16 & 5.05 & 12.53 \\
-0.55 & 6.43 & 1.12 & 4.16 & 5.05 & 12.39 \\
-0.56 & 6.63 & 1.23 & 4.25 & 5.21 & 12.33
\end{tabular}




\section{Conclusion}

Thus, the compositions of the cerium(IV) complexes with 8-hydroxyquinoline and 8-hydroxy-7-iodoquinoline-5-sulfonic acid and also their stability constants, $\log \bar{\beta}_{1}=15.54 \pm 0.13$ for $[\mathrm{CeOHOxiN}]^{2+}$ and $\log \bar{\beta}_{1}=12.38 \pm 0.11$ for $[\mathrm{CeOHFer}]^{+}$, were determined spectrophotometrically and $\mathrm{pH}$-metrically by the kinetic analogues of the thermodynamic methods for investigating the formation of variable-valence metal complexes at an ionic strength $I=2 \mathrm{~mol} / \mathrm{L}$ in a sulfuric acid medium and a temperatures of 275.15 $289.15 \mathrm{~K}$.

\section{Funding details}

No.

\section{Acknowledgements}

None

\section{Conflict of interest}

Author declares that there is no conflict of interest.

\section{References}

1. Oliveri V, Vecchio G. 8-Hydroxyquinolines in medicinal chemistry: A structural perspective. Eur J Med Chem. 2016;120:252-274.

2. Suwanjang W, Prachayasittikul S, Prachayasittikul V. Effect of 8hydroxyquinoline and derivatives on human neuroblastoma SH-SY5Y cells under high glucose. PeerJ. 2016;4:e2389.

3. Soroka K, Vithanage RS, Phillips DA, et al. Fluorescence Properties of Metal Complexes of 8-Hydroxyquinoline-5-sulfonic Acid and Chromatographic Applications. Anal Chem. 1967;59:629-636.
4. Petrova OB, Anurova MO, Akkuzina AA. Luminescent hybrid materials based on (8-hydroxyquinoline)-substituted metal-organic complexes and lead-borate glasses. Opt Mater. 2017;69:141-147.

5. Kolthoff IM, Belcher R, Stanger VA, et al. Volumetric Analysis, Vol. III - Titration Methods: Oxidation-Reduction Reactions. New York: Interscience; 1957

6. Voskresenskaya O, Kinetic and Thermodynamic Stability of Cerium(IV) Complexes with a Series of Aliphatic Organic Compounds. New York: Nova Science Pudlishers, Inc.; 2013.

7. Voskresenskaya OO, Skorik NA, Yuzhakova YuV. Thermodynamics of the Formation of Cerium(IV) Malonate Complex and the Kinetics of Its Redox Decomposition. Russ J Phys Chem A. 2017;91(4):627-633.

8. Pondit AK, Das A, Banerjea D. Kinetics and mechanism of oxidation of 8-hydroxyquinoline and its derivatives by cerium(IV) through precursor complex formation. Trans Met Chem. 1991;16:324-327.

9. Näsänen R, Lumme P, Mukula AL. Potentiometric and Spectrophotometric Studies on 8-Quinolinol and Its Derivatives. I. Ionization of 8-Quinolinol in Aqueous Solutions of Potassium Chloride. Acta Chem Scand. 1951;5:1199-1208.

10. Näsänen R, Ekman A. Potentiometric and Spectrophotometric Studies on 8-Quinolinol and Its Derivatives. V. Ionization of 8-Quinolinol-5Sulfonic Acid and 7-Iodo-8-Quinolinol-5-Sulfonic Acid in Aqueous Solution. Acta Chem Scand. 1952;6:1384-1390.

11. Langmyhr FG, Storm ÅR. Complex Formation of Aluminium with 7 Iodo-8-hydroxy-quinoline-5-sulphonic Acid (Ferron). Acta Chem Scand. 1961;7:1461-1466.

12. Skorik NA, Chernov EB. Computer Computations in Complex Compounds Chemistry. Tomsk: TGU; 2009. 